\title{
Long-Term Cycling of the Magnesium Hydrogen System
}

Pedersen, Allan Schrøder; Kjøller, John; Larsen, Bent; Vigeholm, B.; Jensen, Jørgen Arendt

Published in:

International Journal of Hydrogen Energy

Link to article, DOI:

10.1016/0360-3199(84)90283-0

Publication date:

1984

Document Version

Publisher's PDF, also known as Version of record

Link back to DTU Orbit

Citation (APA):

Pedersen, A. S., Kjøller, J., Larsen, B., Vigeholm, B., \& Jensen, J. A. (1984). Long-Term Cycling of the Magnesium Hydrogen System. International Journal of Hydrogen Energy, 9(9), 791-802.

https://doi.org/10.1016/0360-3199(84)90283-0

\section{General rights}

Copyright and moral rights for the publications made accessible in the public portal are retained by the authors and/or other copyright owners and it is a condition of accessing publications that users recognise and abide by the legal requirements associated with these rights.

- Users may download and print one copy of any publication from the public portal for the purpose of private study or research.

- You may not further distribute the material or use it for any profit-making activity or commercial gain

- You may freely distribute the URL identifying the publication in the public portal

If you believe that this document breaches copyright please contact us providing details, and we will remove access to the work immediately and investigate your claim. 


\title{
LONG-TERM CYCLING OF THE MAGNESIUM HYDROGEN SYSTEM
}

\author{
A. S. Pedersen, J. Kuøller, B. Larsen, B. Vigeholm and J. A. Jensen \\ Risø National Lab., DK-4000 Roskilde. Denmark
}

(Received 19 December 1983)

\begin{abstract}
Magnesium powder with a grain size of approximately $50 \mathrm{um}$ was hydrogenated for $30 \mathrm{~min}$ and dehydrogenated the same time at $390^{\circ} \mathrm{C}, 515$ times. A moderate loss in hydrogen storage capacity was observed and was ascribed to a measured decrease in reaction kinetics as the cycle number increased. The time for maximum hydrogen absorption was found to depend significantly on cycle number while the time for maximum desorption was found to be virtually independent of cycle number.
\end{abstract}

\section{INTRODUCTION}

The technological and scientific interest in metals as hydrogen storage systems has increased during the last decennium. However, many of those systems which are generally considered most promising suffer from materials shortages or high prices (e.g. $\mathrm{LaNi}_{5}, \mathrm{Mg}_{2} \mathrm{Ni}$, $\mathrm{FeTi}$ ). On this ground it is natural that especially the cheap and abundant magnesium has attracted still more attention, in spite of some early, quite negative results on the hydrogenation/dehydrogenation of this metal [1]. It has been demonstrated [2] that finely comminuted magnesium metal (in powder form with a grain size of approximately $50 \mu \mathrm{m}$ or less) readily absorbs hydrogen without any noticeable activation process. Likewise it has been demonstrated [3-4] that magnesium hydride just as readily dissociates to reform the starting materials: magnesium and hydrogen.

If the magnesium-hydrogen system is to be of any practical importance it is essential that the system can undergo the cyclic metamorphosis of the hydrogenation and dehydrogenation sufficiently many times to economically justify the utilization. Exactly how many times this means cannot be said unconditionally. The number will depend on many factors like materials prices, storage times, the application in question, etc. It is the aim of the present paper to report our findings on cycling of the magnesium hydrogen system 500 times.

\section{AUTOMATIC CYCLING APPARATUS}

In order to complete a great number of hydrogenation cycles within a short time we built an automatic cycling equipment controlled by a microcomputer. The equipment is described in detail elsewhere [5]. Here we shall just give an outline of the principles. Figure 1 shows a diagram of the equipment. The measuring technique is based on the measurement of pressure and temperature in known volumes. Before the start of a cycle, volume B was filled with hydrogen. Then the preheated oven was lowered to heat the sample to approx. $390^{\circ} \mathrm{C}$. When the reaction temperature was reached, the three-way valve $\mathrm{V} 2$ was turned to allow the gas into the reaction chamber $\mathrm{A}$. The pressure in $\mathrm{A}$ was kept con- stant by the reduction valve RV throughout the reaction even though the pressure in $\mathrm{B}$ decreased. The pressure drop in B was used to calculate the amount of hydrogen taken up by the sample. After $30 \mathrm{~min}, \mathrm{~V} 2$ was closed and the oven elevated. When the sample had cooled down to $80^{\circ} \mathrm{C}$ the volumes $\mathrm{A}$ and $\mathrm{D}$ were evacuated to $10^{-2}$ bar, and then the oven was lowered to heat the sample to $c a 390^{\circ} \mathrm{C}$. At this temperature valve V2 was opened towards $\mathrm{D}$ and the increase in pressure during 30 min was measured to calculate the amount of hydrogen released. Finally the oven was elevated to complete the cycle. Figure 2 shows the correlated values of the temperature and three pressures $\mathrm{PA}, \mathrm{PB}$ and $\mathrm{PD}$ during one full cycle.

Since the sample consisted of fine powder, it was necessary to construct a container which would prevent powder particles from spreading to the entire system with the expanding gas. The sample container was made of stainless steel and closed by a porous disc.

The pressures were measured by means of piezoresistive transducers (Kistler) with an overall precision better than $1 \%(0-50$ bar $)$. The temperature was measured with a thermocouple ( $\mathrm{NiCr}-\mathrm{Ni})$. Two points should be stressed in connection with the temperature measurement. First, we had an unfavorable temperature profile over the sample container in consequence of an inappropriate oven design. Since the powder tended to spread to all available volume, this means that the measured temperature was not accurately representative for the whole sample. As a consequence of this fact, we obtained misleading results in some cases

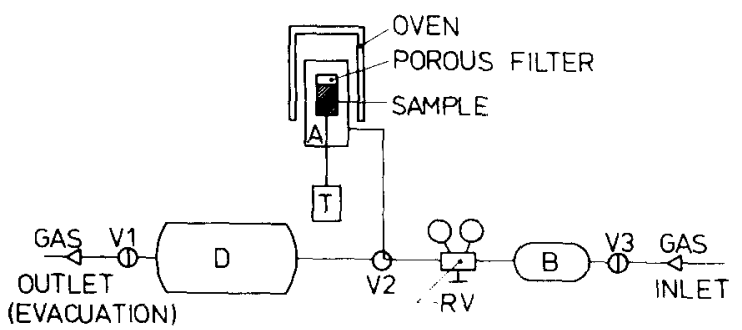

Fig. 1. Schematic diagram of the equipment. 


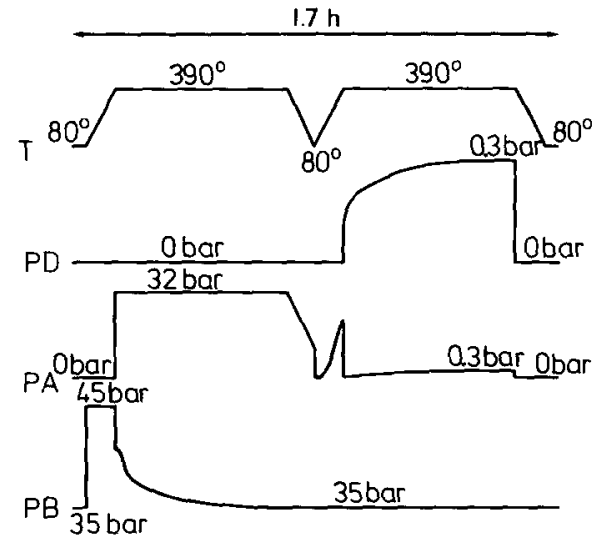

Fig. 2. Correlated values of the temperature and the pressures during one cycle.

(cf. the Results section). Secondly, the absorptions were all carried out at a formally constant temperature. It is well known that the heat of reaction causes the temperature within the individual grains to rise considerably during absorption and fall during desorption. For these reasons the significance of the measured temperature should not be overrated. We consider it merely one of those initial conditions determining the development of the reaction.

\section{MATERIALS}

For the cycling experiment we used hydrogen of $99.9997 \%$ purity, the main impurities being $\mathrm{H}_{2} \mathrm{O}$ $(2 \mathrm{ppm}), \mathrm{N}_{2}(0.5 \mathrm{ppm})$ and $\mathrm{O}_{2}(0.5 \mathrm{ppm})$. The gas was delivered by L'Air Liquide. The magnesium material used was a commercially available powder quality, supplied by Baudier, France. The powder was specified as 33-75 $\mu \mathrm{m}$ containing $\mathrm{Si}$ and $\mathrm{Mn}$ as the main metallic impurities, $1000 \mathrm{ppm}$ each. The oxide content of the magnesium powder was determined by dissolving the $\mathrm{MgO}$ in $1 \mathrm{~N}$ acetic acid and determination of dissolved magnesium by flame atomic absorption. Four independent analyses were made and showed 1.8, 2.4, 2.1 and
$2.2 \% \mathrm{MgO}$. The analyses were carried out by Norsk Hydro Research Centre, Analysis Department.

\section{RESULTS}

\section{A. Capacity}

Figure 3 shows the amount of hydrogen stored within $30 \mathrm{~min}$, as measured by the desorptions versus cycle number. The hydrogen was stored at 32 bar and approximately $390^{\circ} \mathrm{C}$. It was released under vacuum $(0-0.3$ bar) at the same temperature. It should be noted that the anomalous behaviour seen in the ranges of cycle numbers $5,60-75,125-135$ and $215-220$ is caused by an inadvertent movement of the powder (within the sample holder) out of the zone of appropriate reaction temperature. If these specific results are disregarded, a steady decrease in the amount of stored hydrogen is observed as the cycle number increases. The decrease seems to become smaller with increasing cycle number, i.e. the second order derivative is positive. The amounts of stored hydrogen in the cycle number range $500-515$ are large because of a prolonged reaction period. In these cycles the powder was allowed to react for $8 \mathrm{~h}$, resulting in a considerably higher absorption capacity.

\section{B. Kinetics}

The amount of reacted hydrogen versus time is shown in Fig. 4 for the absorption and in Fig. 5 for the desorp-

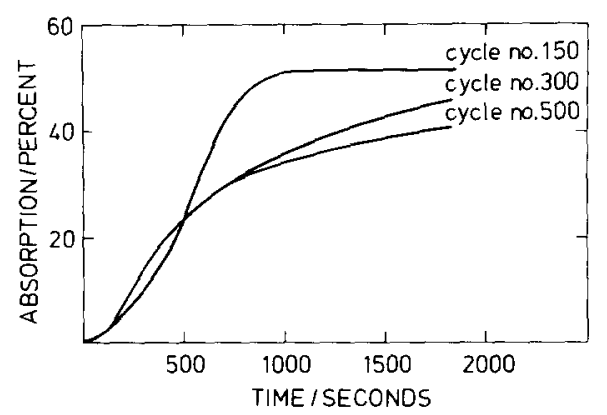

Fig. 4. Time-dependence of the hydrogen absorption (\%).

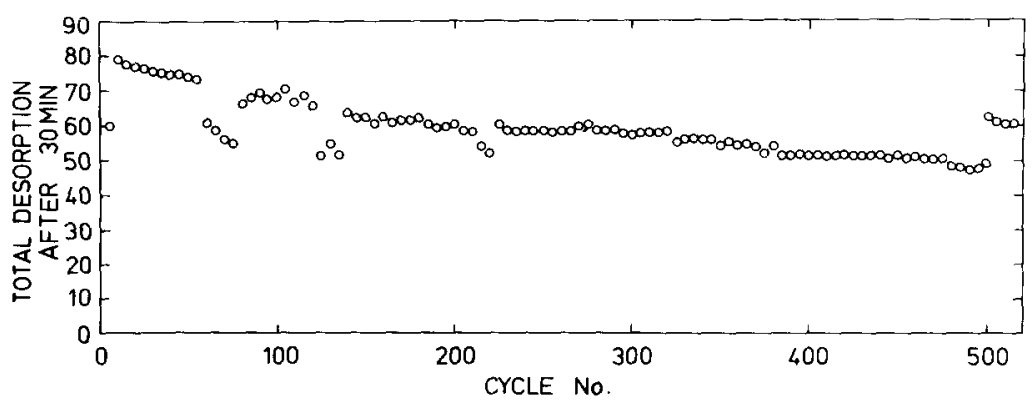

Fig. 3. Storage capacity (\% of theoretically obtainable stoichiometry) versus cycle number. 


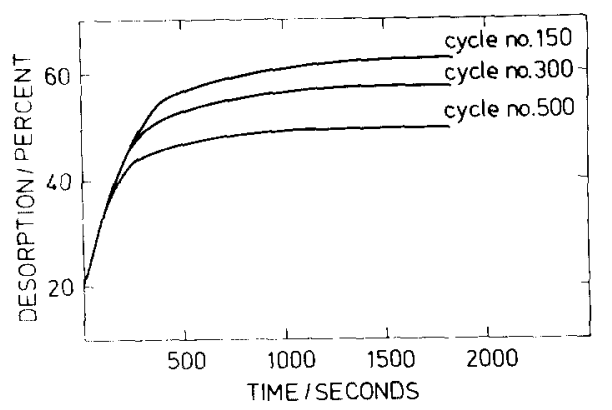

Fig. 5. Time-dependence of the hydrogen desorption $(\%)$.

tion. The figures illustrate the characteristic times for the reactions. The rate of reaction did not vary noticeably as a function of cycle number in the case of the desorption as indicated by Fig. 5 . In contrast to this Fig. 4 shows for the absorption that $30 \mathrm{~min}$ was increasingly an insufficient time for the reaction to be completed as the cycle number increased.

\section{Scanning Electron Microscopy}

SEM micrographs of the powder taken at $300 \times$ magnification are shown in Figs 6 and 7 . As has been observed many times before, the morphology of the sample has changed drastically as a result of the hydrogen treatment.

\section{DISCUSSION}

The fall in storage capacity shown in Fig. 3 can be partly explained by a continuous reaction between the magnesium powder and impurities in the hydrogen gas used for the experiment. Such a reaction will transform hydrogen-active magnesium metal into passive magnesium oxide (presumably magnesium nitride is not formed even though nitrogen is present in the hydrogen gas). Under the assumption that all available impurity gas in our experiment actually reacted with the magnesium powder, we calculated the impurity reaction to imply a maximum passivation of about $0.002 \%$ of the magnesium per cycle. Even if the calculation is in error by a factor of 10 , it is obvious that the observed fall in storage capacity mainly occurs for other reasons. These reasons must be intimately connected with the materials characteristic parameters or rather the change of them. Probably the most important reason for the observed fall in storage capacity is the slower kinetics with increasing cycle number. In the experiment the absorption was performed for $30 \mathrm{~min}$ and then stopped. As the rate of absorption decreases, this means that the total amount of hydrogen absorbed also decreases. The effect is simply a matter of non-equilibrated systems, as also indicated by the positive time-derivative at $t=1800 \mathrm{~s}$

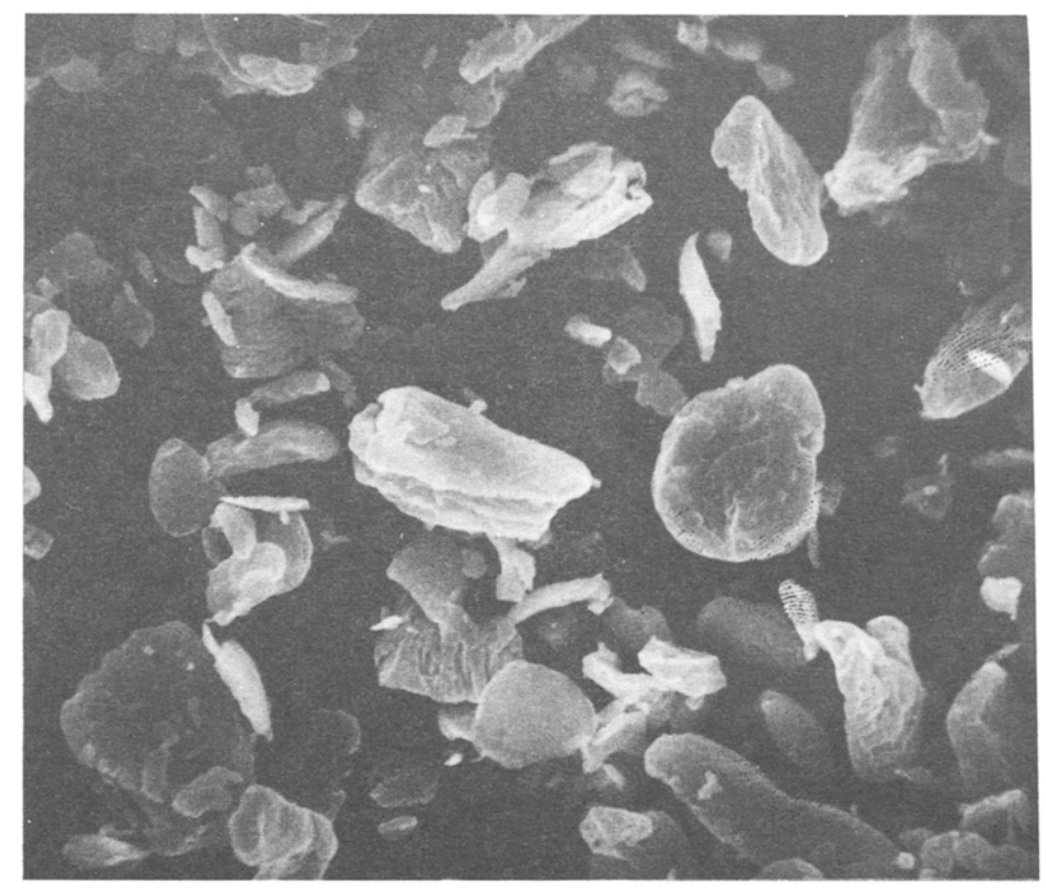

Fig. 6. Magnesium powder prior to hydrogen exposure, $300 \times$. 


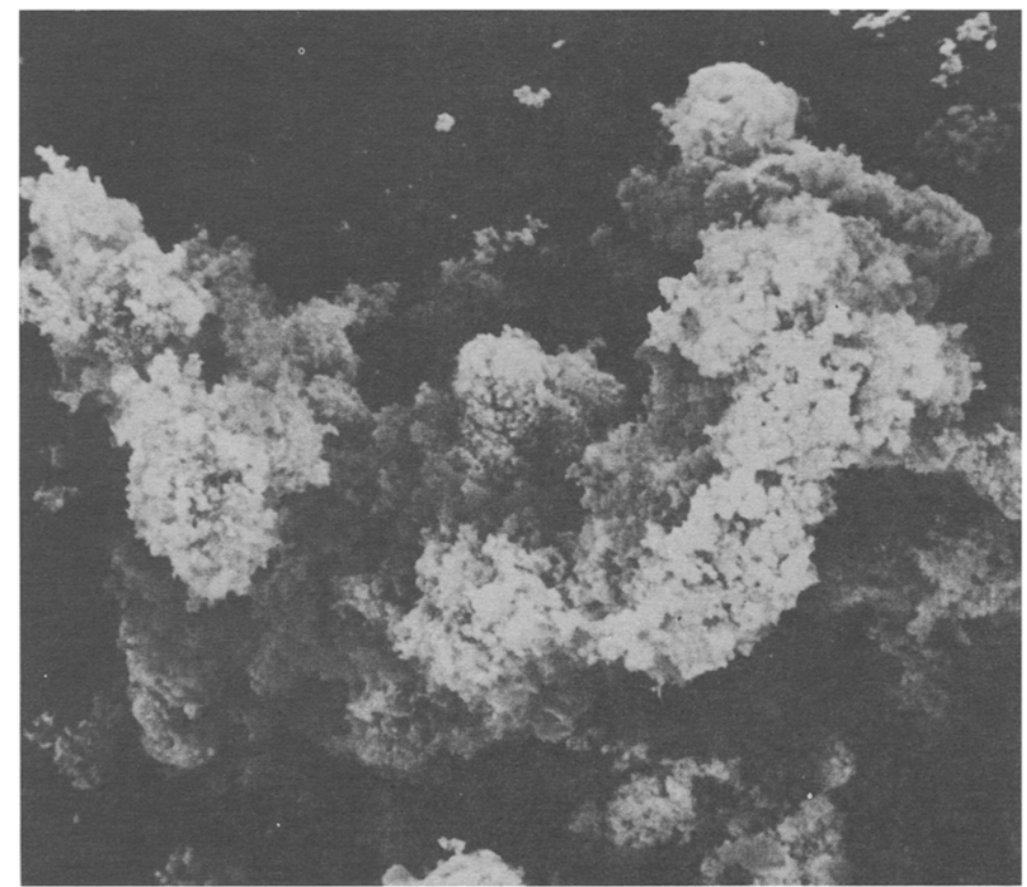

Fig. 7. Magnesium hydride after 515 cycles, $300 \times$.

in Fig. 4. If the $30 \mathrm{~min}$ absorption is surpassed, as in cycles $500-515$, a rather large increase in storage capacity is observed, making the capacity comparable with that at low cycle numbers.

At the present stage, the reason for the observed reaction rates is speculative. We tentatively suggest that grain growth takes place as a result of the high reaction temperatures (during absorptions above $400^{\circ} \mathrm{C}$ within individual particles). Since the hydrogen diffusion preferentially occurs in the grain boundaries, the recrystallization process disfavors the diffusion into the interior of the particles, thereby causing the observed effect on the absorption kinetics.

\section{CONCLUSIONS}

Magnesium powder with a grain size of approximately
$40 \mu \mathrm{m}$ or less is a suitable material for repeated storing of hydrogen. The loss in storage capacity during 500 cycles is small and is not a hindrance for the utilization of this material for energy storage purposes.

\section{REFERENCES}

1. B. Tanguy, J-L. Soubeyroux, M. Pezat, J. Portier and P. Hagenmuller, Mater. Res. Bull. 11, 1481 (1976).

2. C. M. Stander, Z. phys. Chem. N.F. 104, 229 (1977).

3. A. S. Pederson, J. Kjøller, B. Larsen and B. Vigeholm, Int. J. Hydrogen Energy 8, 205 (1983).

4. B. Vigeholm, J. Kjøller, B. Larsen and A. S. Pedersen, J. Less-Common Metals 89, 135 (1983).

5. B. Vigeholm, Final report on Contract No. EHC-14-009Dk financed by the Commission of the European Communities. 